\title{
ATTITUDES OF THE MEDICAL STUDENTS FROM TWO CZECH UNIVERSITIES TO PANDEMIC FLU A (H1N1) 2009 AND TO INFLUENZA VACCINATION
}

\author{
Hana Tomášková', , Sylva Boháčová1, Hana Šlachtová2 \\ 'Department of Epidemiology and Public Health, Faculty of Medicine, University of Ostrava, Czech Republic \\ ${ }^{2}$ Institute of Public Health, Ostrava, Czech Republic
}

\section{SUMMARY}

Objectives: The aim of the study was to find out the approach of students to vaccination against seasonal influenza, how they perceived risk associated with influenza pandemic, and whether the pandemic influenced their approach to vaccination against seasonal flu.

Methods: Data collection was conducted through an anonymous questionnaire survey. Distribution and collection of questionnaires took place from November to December 2010 at the medical faculties of two universities. Out of the total 360 distributed questionnaires, 343 were filled. The qualitative data were analysed using $\chi^{2}$ test and Fisher's exact test. The analysis of variance (ANOVA) and two-sample t-test were used for the evaluation of quantitative data. Statistical tests were performed at a significance level of 5\% in STATA 10.

Results: The proportion of students regularly vaccinated against seasonal flu was low (4\%). Students rated the risk of pandemic influenza A (H1N1) in 2009 as relatively low and an interest in vaccination did not increase even during the pandemic and consequently only $5 \%$ expressed their interest to get vaccinated during the pandemic. However, only $3 \%$ of respondents were vaccinated at the time of vaccine availability. In the following year, only $5 \%$ of respondents planned to get vaccinated against seasonal influenza.

Conclusion: The results of the questionnaire study indicate that young people have not perceived vaccination against influenza as an important anti-epidemic measure and their opinion have not changed even during the outbreak of pandemic influenza A (H1N1) in 2009.

Key words: influenza, vaccination, risk perception, students

Address for correspondence: Hana Tomášková, Department of Epidemiology and Public Health, Faculty of Medicine, University of Ostrava, Syllabova 19, 70300 Ostrava, Czech Republic. E-mail: hana.tomaskova@osu.cz

\section{INTRODUCTION}

The first case of infection of influenza A (H1N1) 2009 in the Czech Republic was confirmed on May 23rd, 2009. The patient was a twenty-nine years old pilot who returned from New York. A course of the disease was moderate without the need of hospitalization.

Since September 1st, the National Reference Laboratory has launched a sentinel system for sampling of biological material to monitor virus circulation in the country. A slight increase of positive cases occurred around 30th calendar week, but the infections were mostly imported. The second wave, characterized by a rapid increase in morbidity, lasted from November 2009 to January 2010. The first case of death caused by a new type of virus was confirmed by the National Reference Laboratory on October 23rd, 2009. The victim was a 31 year old woman with complicated course of the disease.

Out of the total 2,477 laboratory-confirmed cases, 102 cases have been fatal. In the Czech Republic as well as in the world 90\% of victims were younger than 65 years. At approximately $75 \%$ of fatal cases accompanying serious diseases were diagnosed (1-3).

The Czech Republic signed a contract to purchase one million Pandemrix pandemic vaccines. Primarily, approximately two thirds of vaccines were intended for chronically ill people and pregnant women, the rest for health professionals and state authorities. The vaccination started on November 25th, 2009. Selected groups were, however, not interested in vaccination and therefore, this was offered on free basis to the general population. The vaccination was finished on May 31st, 2010. Nearly 70 thousands out of the total number of approximately 10 million inhabitants underwent vaccination during the entire period.

The aim of this work based on a questionnaire survey in medical students was to find out what was the approach of students to vaccination against seasonal influenza, how they perceived risk associated with influenza pandemic, and whether the pandemic influenced their attitude to vaccination against seasonal flu.

\section{MATERIALS AND METHODS}

Data collection was conducted through an anonymous questionnaire survey. A structured questionnaire that contained 13 closed and opened questions was created for this study. Distribution and collection of questionnaires was conducted from November to December 2010 at the medical faculties of the two universities - the University of Ostrava and the Masaryk University in Brno. The study sample consisted of randomly selected students enrolled in the first to the sixth semester 
present at school and willing to participate in the study. Out of the total 360 distributed questionnaires, 343 were filled in, i.e. response-rate of $95 \%$.

Data from questionnaires were entered into the program EpiData (4). After the data control and data cleaning the descriptive statistics (mean, standard deviation and frequency tables) was performed. The qualitative data were analysed using $\chi^{2}$ test and Fisher's exact test. The analysis of variance (ANOVA) and twosample t-test were used for the evaluation of quantitative data. Statistical tests were performed at a significance level of $5 \%$ in STATA version 10 (5).

\section{RESULTS}

Approximately three quarters of the questionnaires were distributed and filled in by students from the University of Ostrava (Table 1). The largest part of the sample consisted of general medicine students $(36 \%)$ and public health $(22 \%)$ students. In total $15 \%$ (50/343) of men and $85 \%$ (293/343) of women participated in the study. The average age of the whole study sample was 21.3 years.

Of the total, only $4 \%$ of students were vaccinated regularly and $13 \%$ of them occasionally against seasonal influenza. In total, $83 \%$ of students have never been vaccinated against flu. The statistically significant difference was found in vaccination against seasonal influenza between women and men $(p=0.024)$. Two times more women compared to men were regularly vaccinated, but a higher percentage of men than women indicated occasional vaccination. Up to $70 \%$ of students, who have never been vaccinated, reported as the main reason perceived unimportance of vaccination (Table 2).

The average risk of falling ill with a pandemic flu was rated on a scale from 0 to 10 and reached the value of 3.8. A higher risk was perceived by women $(p<0.001)$. The results showed the highest perceived risk among the students of public health, but no statistically significant difference was found between the fields of study (Table 3).

Most of the students drew information about pandemic influenza A (H1N1) in 2009 from the media, half of the students also exploited professional sources or were informed by their physician (Table 4). A significant difference $(p=0.010)$ in the use of professional resources or information from a physician was found between the students according to the field of study. These sources were preferred in 52\% (65/125) of students of general medicine, $33 \%(25 / 75)$ of public health students and $36 \%$ $(52 / 143)$ of students from the other fields of study.

The results of the questionnaire study confirmed that only $9 \%$ $(31 / 343)$ of students followed some of the recommended preventive measures (beyond common measures such as hand washing). The most frequently applied measures were travel restrictions to areas with a high incidence of the disease, reduction of frequent social contacts and staying away from public crowds (Table 4).

Only a little interest in the vaccination against pandemic flu was detected among students. Only 5\% (18/343) of respondents wanted to get vaccinated. Slightly greater, but statistically not significant interest was observed among men $(8 \%, 4 / 50)$ compared to women $(5 \%, 14 / 293)$.

Table 1. Distribution of students by the university and field of study

\begin{tabular}{|l|c|c|c|c|}
\hline University/Field of Study & General Medicine & Public Health & Other* & $\begin{array}{c}\text { Total } \\
\text { number (\%) }\end{array}$ \\
\hline University of Ostrava & 96 & 74 & 84 & $254(74 \%)$ \\
\hline Masaryk University & 29 & 1 & 59 & $89(26 \%)$ \\
\hline Total number of students & 125 & 75 & 143 & $343(100 \%)$ \\
\hline
\end{tabular}

*Other fields of study - ergo-therapy, orthotics-prosthetics, general nurse, physiotherapy, nutritional therapist, paramedic and midwife

Table 2. Distribution of students by frequency of vaccination against seasonal influenza and reasons of refusal in unvaccinated students

\begin{tabular}{|c|c|c|c|c|c|c|c|c|}
\hline \multirow{4}{*}{ Vaccination* } & \multicolumn{6}{|c|}{ Frequency } & \multirow{2}{*}{\multicolumn{2}{|c|}{ Total }} \\
\hline & \multicolumn{2}{|c|}{ Regularly } & \multicolumn{2}{|c|}{ Occasionally } & \multicolumn{2}{|c|}{ Never } & & \\
\hline & $\mathrm{N}$ & $\%$ & $\mathbf{N}$ & $\%$ & $\mathrm{~N}$ & $\%$ & N & $\%$ \\
\hline & 15 & 4 & 43 & 13 & 285 & 83 & 343 & 100 \\
\hline \multicolumn{9}{|l|}{ Reasons of refusal ${ }^{* *}$} \\
\hline Vac. is not safe & $x$ & & 4 & 9 & 24 & 8 & 28 & 8 \\
\hline Vac. is not important & $x$ & & 19 & 44 & 199 & 70 & 218 & 64 \\
\hline Lack of finance & $x$ & & 5 & 12 & 19 & 7 & 24 & 7 \\
\hline Lack of time & $x$ & & 5 & 12 & 3 & 1 & 8 & 2 \\
\hline Others & $x$ & & 10 & 23 & 34 & 12 & 44 & 13 \\
\hline Missing & $x$ & & 0 & 0 & 6 & 2 & 6 & 2 \\
\hline
\end{tabular}

*row percentage, ${ }^{* *}$ column percentage 
Table 3. Risk perception in response to 2009 (H1N1) pandemic influenza by sex and fields of study

\begin{tabular}{|c|c|c|c|c|}
\hline \multirow{2}{*}{ Sex/Field of study } & \multirow{2}{*}{$\mathrm{N}$} & \multicolumn{2}{|c|}{ Risk perception* } & \multirow{2}{*}{ P-value } \\
\hline & & Mean & SD & \\
\hline Men & 50 & 2.7 & 1.7 & \multirow{2}{*}{$<0.001$} \\
\hline Women & 293 & 3.9 & 2.0 & \\
\hline General medicine & 125 & 3.7 & 2.1 & \multirow{3}{*}{0.099} \\
\hline Public health & 75 & 4.2 & 1.9 & \\
\hline Others & 143 & 3.6 & 1.9 & \\
\hline Total number & 343 & 3.8 & 2.0 & \\
\hline
\end{tabular}

Statistically significant difference in the vaccination take up was found out between the fields of study $(p<0.001)$. The greatest interest was expressed by students of general medicine $11 \%$ (14/125), followed by students of public health 4\% (3/75), with less than $1 \%(1 / 143)$ of students of the other fields interested in vaccination. However, only $3 \%(11 / 343)$ of respondents were vaccinated at the time of vaccine availability.

Regardless of the above, the main reason for not being more interested in vaccination at the time of vaccine availability students stated the lack of perception of its importance at that time. This reason was mentioned by $56 \%$ (184/325) of respondents.

In the following year, only $5 \%(18 / 343)$ of respondents expressed their interest to be vaccinated against seasonal influenza.

\section{DISCUSSION}

Only $4 \%$ of respondents regularly and $13 \%$ of them occasionally took up vaccination against seasonal influenza. With 10-15\% (6) vaccination coverage of population, the Czech Republic ranks among countries with the lowest seasonal flue vaccination take up in Europe (3).

Vaccination coverage was higher among persons aged over 65 years (20-23\%) and those at a high risk (19-20\%). The highest vaccination coverage was found in the group of people over 65 years of age with chronic illness (40\%) (6). Similar vaccination coverage patterns are also reported in other neighbouring countries $(7,8)$.

The main reason of vaccination refusal was that the respondents did not consider vaccination against influenza to be important. The most common reason indicated in other studies is a fear of side effects (9-12).

Respondents rated the risk of becoming ill with pandemic flu as low, the same as the general population in Germany (11). Similarly, the risk was perceived by the most of students in Australia (13) where the research was conducted at the pandemic peak period. Low to medium risk was perceived also by students from Turkey (9). Population in Hong Kong had perceived a high risk of pandemic flu at the beginning of follow up survey (April 2009), but until November 2009 the perceived epidemic danger was reduced (14). Women perceived the risk of becoming ill with pandemic influenza significantly more than men. This difference was also found in other studies, in the population of university students $(9,13)$ as well as in the general population (15-17).

The main source of information during a pandemic was the media, similarly to the study in Turkish students (9). Nowadays, the influence of the media cannot be ignored. Contradictory information in the media about the vaccine against pandemic influenza A (H1N1) in 2009 may also have affected a low interest of respondents to get vaccinated. The interest was expressed only by $5 \%$ of respondents. But only $3 \%$ was really vaccinated when the vaccine was available. Similar results were obtained also by Akan et al. (9), where only $7 \%$ of the students expressed an interest in vaccination. Overall, in the Czech Republic, only $0.7 \%$ of the population was vaccinated against pandemic flu. In Norway, Sweden and the Netherlands the vaccination take up reached $70-80 \%$ during the flu season. A systematic literature review of the determinants of 2009 pandemic A/H1N1 influenza vaccination based on twenty-seven studies from twelve countries reported the pandemic influenza vaccine coverage from $4.8 \%$ to $92 \%$ (18).

The vaccination coverage in medical students (3\%) was higher than in the general Czech population $(0.7 \%)$ and that corresponds with results from other studies reporting higher pandemic influenza vaccination in male sex, younger age, higher education, and being a doctor (18), and varying also by race/ethnicity, income, and education level (19).

Table 4. Sources of information and preventive measures applied during the pandemic influenza A (H1N1) in 2009

\begin{tabular}{|c|c|c|c|}
\hline Answer & Yes & No & Total \\
\hline Source of information & $\mathrm{N}(\%)$ & $N(\%)$ & $\mathrm{N}(\%)$ \\
\hline Media (TV, radio, internet - lay article) & $315(92 \%)$ & $28(8 \%)$ & $343(100 \%)$ \\
\hline Professional sources (scientific journals, internet - health institutions) & $111(32 \%)$ & $232(68 \%)$ & $343(100 \%)$ \\
\hline Physician (general, specialist) & $59(17 \%)$ & $284(83 \%)$ & $343(100 \%)$ \\
\hline Others & $23(7 \%)$ & $320(93 \%)$ & $343(100 \%)$ \\
\hline Measure & $31(9 \%)$ & $312(91 \%)$ & $343(100 \%)$ \\
\hline Travel restrictions to areas with a high incidence of the disease & $16(52 \%)$ & $15(48 \%)$ & $31(100 \%)$ \\
\hline Reduction of close contacts among people, staying away from public gathering & $13(42 \%)$ & $18(58 \%)$ & $31(100 \%)$ \\
\hline Acquisition of medicament reserve, protective equipment & $6(19 \%)$ & $25(81 \%)$ & $31(100 \%)$ \\
\hline Travel restrictions in general & $6(19 \%)$ & $80(81 \%)$ & $31(100 \%)$ \\
\hline Others & $1(3 \%)$ & $30(97 \%)$ & $31(100 \%)$ \\
\hline
\end{tabular}


The most common preventive measure that has been applied in the respondents' families during the pandemic was travel restrictions to areas with a high incidence of disease and social distancing of frequent contacts and staying away from public crowds. Similar results were obtained in Turkey (9) and Hong Kong (14) where one of the most common preventive measures was isolation.

Pandemic influenza A (H1N1) in 2009 did not raise influenza vaccination concerns of respondents in the following season. Only about $5 \%$ of respondents planned to be vaccinated. Perceived low risk of pandemic flu in students was the reason for their rather slack attitude to the vaccination.

\section{CONCLUSIONS}

The proportion of students being regularly vaccinated against seasonal flu was lower (4\%) compared to the general Czech population. The major reason for vaccination refusal was the respondents' perception of the lack of seasonal flu vaccination importance.

Respondents rated the risk of pandemic influenza A (H1N1) 2009 as relatively low, with significantly higher perception of the risk by women compared to men. Even the unfavourable epidemiological situation did not increase the future interest in vaccination against pandemic flu among respondents.

Only $5 \%$ reported that they would be interested in vaccination during the pandemic. However, only $3 \%$ of respondents were really vaccinated when the vaccine was available.

Only $5 \%$ of respondents considered vaccination against seasonal influenza in the coming flu season. The results of the questionnaire study indicate that young people did not perceive vaccination against influenza to be important and their opinion has not even been changed in view of the consequences of pandemic A (H1N1) in 2009.

\section{Acknowledgement}

The authors thank to all students who participated in the questionnaire survey, and also to Vladimir Plesnik, MD for his valuable comments.

\section{Conflicts of interest}

None declared

\section{REFERENCES}

1. National Institute of Public Health. Influenza [Internet]. Prague: National Institute of Public Health [cited 2012 May 23]. Available from: http:// www.szu.cz/tema/prevence/mexicka-praseci-chripka. (In Czech.)

2. Plíšek S, Kosina P, Chlíbek R, Prášil P, Kračmarová R, Gebouský P, et al. Analysis of 2009 pandemic influenza A(H1N1) cases in East Bohemia region. Vakcinologie. 2010;4(4):138-43. (In Czech.)
3. World Health Organization. Influenza. Global influenza programme [Internet]. Geneva: WHO; 2012 [cited 2012 May 23]. Available from: http://www.who.int/csr/disease/influenza/en/index.html.

4. Lauritsen JM, Bruus M. EpiData (version 3). A comprehensive tool for validated entry and documentation of data. Odense, Denmark: EpiData Association; 2003.

5. StataCorp. Stata statistical software: release 10. College Station, TX: StataCorp; 2007.

6. Blank PR, Schwenkglenks M, Szucs TD. Vaccination coverage rates in eleven European countries during two consecutive influenza seasons. J Infect. 2009 Jun;58(6):446-58.

7. Seligová J, Čulmanová A, Krištufková Z, Čisláková L, Hudečková H. Changes in surveillance of acute respiratory infections including influenza in the Slovak Republic during 1993-2008. Cent Eur J Public Health. 2011 Mar;19(1):20-5.

8. Nitsch-Osuch A, Wardyn K. Influenza vaccine coverage in age-related risk groups in Poland, 2004-2007. Cent Eur J Public Health. 2009 Dec;17(4):198-202.

9. Akan H, Gurol Y, Izbirak G, Ozdatli S, Yilmaz G, Vitrinel A, et al. Knowledge and attitudes of university students toward pandemic influenza: a cross-sectional study from Turkey. BMC Public Health. 2010 Jul $13 ; 10: 413$.

10. Flood EM, Rousculp MD, Ryan KJ, Beusterien KM, Divino VM, Toback $\mathrm{SL}$, et al. Parents' decision-making regarding vaccinating their children against influenza: a web-based survey. Clin Ther. 2010 Aug;32(8):144867.

11. Walter D, Bohmer M, Reiter S, Krause G, Wichmann O. Risk perception and information-seeking behaviour during the 2009/10 influenza A(H1N1)pdm09 pandemic in Germany. Euro Surveill. 2012 Mar 29;17(13). pii: 20131.

12. de Souza EP, Teixeira Mde S. Pandemic influenza A/H1N1 vaccination coverage, adverse reactions, and reasons for vaccine refusal among medical students in Brazil. Rev Inst Med Trop Sao Paulo. 2012 MarApr;54(2):77-82.

13. Van D, McLaws ML, Crimmins J, MacIntyre CR, Seale H. University life and pandemic influenza: attitudes and intended behaviour of staff and students towards pandemic (H1N1) 2009. BMC Public Health. 2010 Mar $14 ; 10: 130$.

14. Cowling BJ, Ng DM, Ip DK, Liao Q, Lam WW, Wu JT, et al. Community psychological and behavioral responses through the first wave of the 2009 influenza A(H1N1) pandemic in Hong Kong. J Infect Dis. 2010 Sep 15;202(6):867-76.

15. Ibuka Y, Chapman GB, Meyers LA, Li M, Galvani AP. The dynamics of risk perceptions and precautionary behavior in response to 2009 (H1N1) pandemic influenza. BMC Infect Dis. 2010 Oct 14;10:296.

16. Jacobs J, Taylor M, Agho K, Stevens G, Barr M, Raphael B, et al. Factors associated with increased risk perception of pandemic influenza in Australia. Influenza Res Treat. 2010. Article ID 947906. doi:10.1155/2010/947906.

17. de Zwart O, Veldhuijzen IK, Elam G, Aro AR, Abraham T, Bishop GD, et al. Avian influenza risk perception, Europe and Asia. Emerg Infect Dis. 2007 Feb;13(2):290-3. Erratum in: Emerg Infect Dis. 2007 Mar;13(3):522.

18. Brien S, Kwong JC, Buckeridge DL. The determinants of 2009 pandemic $\mathrm{A} / \mathrm{H} 1 \mathrm{~N} 1$ influenza vaccination: a systematic review. Vaccine. $2012 \mathrm{Feb}$ $8 ; 30(7): 1255-64$.

19. Santibanez TA, Singleton JA, Santibanez SS, Wortley P, Bell BP. Sociodemographic differences in opinions about 2009 pandemic influenza A (H1N1) and seasonal influenza vaccination and disease among adults during the 2009-2010 influenza season. Influenza Other Respi Viruses. 2012 May 9. doi: 10.1111/j.1750-2659.2012.00374.x.

Received October 18, 2011 Accepted in revised form June 14, 2012 